\title{
Formulation and evaluation of glipizide tablets utilizing Hibiscus rosasinensis leaves mucilage
}

\author{
Sanjib Bahadur ${ }^{1} *$, Amit Roy ${ }^{1}$, Pragya Baghel ${ }^{1}$, Ananta Choudhury ${ }^{1}$, Suman \\ Saha ${ }^{1}$, Ranabir Chanda ${ }^{2}$
}

\begin{abstract}
${ }^{1}$ Columbia Institute of Pharmacy, Village Tekari, Near Vidhan Sabha, Raipur, Chhattisgarh, 493111, India 2Pratishta Institute of Pharmaceutical Sciences, Durajpally (V), Chivemla (M), Suryapet (Dist.) Telangana, 508214, India
\end{abstract}

Submitted: $20-12-2017$

Revised: 14-02-2018

Accepted: 1-03-2018

${ }^{*}$ Corresponding author Sanjib Bahadur

Email:

sanjib_pharmacist@yahoo.co.in

\begin{abstract}
This research work aims to develop glipizide tablets using Hibiscus rosasinensis leaves mucilage. The mucilage was extracted by using double distilled water and precipitated with ethanol. The precipitated mucilage was dried and grounded into powder. The tablet utilizing the mucilage as excipient was prepared by wet granulation method. The tablets were subjected to various tests. The evaluatory parameters of tablets were found to be within the limits as per United States Pharmacopoeia NF 24/19. FTIR spectrum reveals that there is no incompatibility between the ingredients used. Diabetes was induced in wistar albino rats using streptozotocin and effect of formulation on blood glucose level was determined. It was observed that the formulation could not sustain the release of glipizide. However, the glipizide release was retarded as the amount of mucilage was increased. It was observed that on the completion of antidiabetic study, the formulation could bring the blood glucose level to normal in group rats. However, the blood glucose level was still elevated in group administered with pure gliplizide. It can be concluded that HRM can be used to formulate glipizide tablets. The formulations with HRM shows better hypoglycemic activity and this may be attributed to antidiabetic activity of Hibiscus rosasinensis.
\end{abstract}

Keywords: Hibiscus rosasinensis, glipizide, mucilage, antidiabetic activity, excipients

\section{INTRODUCTION}

The therapeutic efficacy and stability of any formulation not only depends on active pharmaceutical ingredients, but also on the excipients used and manufacturing process (Bahadur et al., 2014). Recently excipients from natural sources have gained tremendous interest amongst researchers. This may be attributed to number of advantages that excipients from natural sources have over excipients from synthetic or semi synthetic sources. Gums and mucilages are hydrocolloids. Gums are produced either by causing injury to the plants or due to some pathological condition. Mucilages are considered to be physiological and normal products of metabolism (Razavi et al., 2014). Naturally occurring mucilages are used extensively these days due to their biodegradable nature, safety, availability and economical. Deficiency of insulin secretion or inaction of insulin leads to a group of metabolic diseases, commonly known as diabetes. This leads to chronic hyperglycemia and causes long term damage to different organs (American Diabetes Association, 2014). According to International Diabetes Federation (IDF), 387 million people have diabetes, which is expected to rise to 592 million by $2035.90 \%$ of diabetics around the world are suffering from type 2 diabetes (Media Centre, 2016). Oral antidiabetic agents can be administered for management of blood glucose level in type 2 diabetes. Glipizide is extensively and widely used for management of glucose level in type 2 diabetic patients. Glipizide is sulphonyl urea antidiabetic agents, having $\mathrm{pKa} 5.9$, partially soluble in water and falls in class II category of drugs according to Biopharmaceutical Classification System (Kambham, Shanthi, 2012). Hibiscus rosasinesis (HR) is commonly known as China rose. The roots are demulcent. 
Table I. Composition of various glipizide tablet formulations

\begin{tabular}{lllllllll}
\hline Ingredients & F1 & F2 & F3 & F4 & F5 & F6 & F7 & F8 \\
\hline Glipizide (mg) & 40 & 40 & 40 & 40 & 40 & 40 & 40 & 40 \\
HRM (mg) & 40 & 60 & 80 & 100 & 120 & 140 & 160 & 200 \\
Microcrystalline cellulose (mg) & 216 & 196 & 176 & 156 & 136 & 116 & 96 & 56 \\
Distilled water (ml) & q.s & q.s & q.s & q.s & q.s & q.s & q.s & q.s \\
Talc (mg) & 2 & 2 & 2 & 2 & 2 & 2 & 2 & 2 \\
Magnesium stearate (mg) & 2 & 2 & 2 & 2 & 2 & 2 & 2 & 2 \\
\hline
\end{tabular}

Leaves and flowers have anti ulcer activity and reported to promote growth and colour of hair. (Sankaran, 2011). Leaf extract of HR is reported to have antidiabetic activity (Moqbel, et al., 2011). The aim of this research work is to develop tablets of glipizide using HR mucilage (HRM) as binder.

\section{MATERIALS AND METHODS}

Glipizide was received as gift sample from Dishman Pharmaceuticals \& Chemicals Ltd, Ahmedabad. Microcrystalline cellulose, Talc and Magnesium Stearate was procured from SD Fine Chemcials Ltd., India. All the other chemicals used were of analytical grades.

\section{Extraction of mucilage}

HR leaves was collected and washed carefully with double distilled water to remove any adherent material. The leaf was grinded with small amount of water using mixer grinder to form slurry. The slurry thus prepared was precipitated in about three times its volume of ethanol with continuous stirring with mechanical stirrer. The precipitate was washed for three times with ethanol and dried at $40 \pm 1^{\circ} \mathrm{C}$. The dried material was ground by a mechanical grinder and passed through \# 60 mesh sieve and kept in a desiccator till further use

\section{Preparation of tablets}

Eight different formulations (F1-F8) were prepared using different proportion of HRM (Table I) by using wet granulation method. HRM powder was sieved through sieve no. 22 separately and mixed with glipizide and microcrystalline cellulose. The mixture was granulated by using sufficient distilled water. The granules were dried in a tray drier at $50^{\circ} \mathrm{C}$. The granules were passed through sieve no. 20 and then lubricated using talc and magnesium stearate (1:1). The granules were compressed on 10 - station tablet compression machine (Shakti Machineries, India) using $10 \mathrm{~mm}$ punches.

\section{Evaluation of prepared tablets \\ Thickness}

The thickness of five tablets was determined using a verniar calliper and average was noted.

Weight variation test

20 tablets were weighed using electronic balance (Denver APX-100, Arvada, Colorado) and test was performed as per the official method of United States Pharmacopoeia (USP).

\section{Drug content}

Five tablets were weighed individually, and the drug was extracted in phosphate buffer $\mathrm{pH}$ 7.4. The absorbance of the extract was recorded by using UV - spectrophotometer (1800, Shimadzu, Japan) at $274 \mathrm{~nm}$. The concentration of drug extracted and then drug content was determined by using standard calibration curve.

\section{Hardness and Friability}

For each formulation, the hardness and friability of 5 and 20 tablets respectively, were determined using the Monsanto hardness tester (Cad-mach, Ahmedabad, India) and the Roche friabilator (Camp-bell Electronics, Mumbai, India).

\section{Drug polymer compatibility studies}

Drug polymer compatibility study was carried out using Infra red spectrophotometer (IR Affinity, Shimadzu, Tokyo, Japan). Prepared tablets were compressed with potassium bromide and transformed into disk. 
Table II. Properties of compressed tablets

\begin{tabular}{|c|c|c|c|c|c|c|}
\hline $\begin{array}{l}\text { Batch } \\
\text { code }\end{array}$ & $\begin{array}{l}\text { Thickness* } \\
\text { (mm) }\end{array}$ & $\begin{array}{c}\text { Deviation in } \\
\text { Weight Variation } \\
\text { Test }(\%)\end{array}$ & $\begin{array}{l}\text { Drug } \\
\text { Content* } \\
(\%)\end{array}$ & $\begin{array}{l}\text { Hardness* } \\
\left(\mathrm{kg} / \mathrm{cm}^{2}\right)\end{array}$ & $\begin{array}{c}\text { Friability }{ }^{\dagger} \\
(\%)\end{array}$ & $\begin{array}{l}\text { Disintegration } \\
\text { Time (min) }\end{array}$ \\
\hline F1 & $3.42 \pm 0.03$ & $3.895 \pm 0.03$ & $95.60 \pm 0.02$ & $5.5 \pm 0.20$ & $0.75 \pm 0.02$ & $4.35 \pm 0.21$ \\
\hline $\mathrm{F} 2$ & $3.45 \pm 0.04$ & $2.876 \pm 0.04$ & $97.96 \pm 0.03$ & $5.0 \pm 0.14$ & $0.88 \pm 0.05$ & $5.54 \pm 0.32$ \\
\hline F3 & $3.39 \pm 0.02$ & $2.987 \pm 0.03$ & $98.37 \pm 0.02$ & $5.3 \pm 0.23$ & $0.85 \pm 0.06$ & $4.24 \pm 0.12$ \\
\hline F4 & $3.36 \pm 0.03$ & $2.167 \pm 0.01$ & $98.92 \pm 0.02$ & $5.5 \pm 0.25$ & $0.36 \pm 0.03$ & $5.76 \pm 0.22$ \\
\hline F5 & $3.45 \pm 0.02$ & $2.567 \pm 0.03$ & $96.55 \pm 0.13$ & $5.6 \pm 0.16$ & $0.72 \pm 0.05$ & $4.51 \pm 0.29$ \\
\hline F6 & $3.38 \pm 0.03$ & $3.125 \pm 0.02$ & $96.51 \pm 0.03$ & $5.7 \pm 0.16$ & $0.73 \pm 0.04$ & $4.87 \pm 0.19$ \\
\hline F7 & $3.45 \pm 0.01$ & $2.987 \pm 0.04$ & $97.50 \pm 0.04$ & $5.8 \pm 0.24$ & $0.68 \pm 0.12$ & $4.48 \pm 0.12$ \\
\hline F8 & $3.38 \pm 0.02$ & $2.541 \pm 0.02$ & $96.79 \pm 0.02$ & $5.4 \pm 0.19$ & $0.70 \pm 0.06$ & $4.35 \pm 0.52$ \\
\hline
\end{tabular}

${ }^{*}$ All values are expressed as mean $\pm \mathrm{SE}, \mathrm{n}=5$; $\dagger$ All values are expressed as mean $\pm \mathrm{SE}, \mathrm{n}=20$

The disk was placed at the centre of sample holder and scanned between $4000-400 \mathrm{~cm}^{-1}$ at resolution $4 \mathrm{~cm}^{-1}$. The spectrum of formulation and glipizide was compared to determine drug polymer compatibility.

\section{In vitro release studies}

Release of glipizide from tablets was studied in USP Apparatus II (Veego, Kolkata, India), paddles at $100 \mathrm{rpm}$ and $37 \pm 0.5^{\circ} \mathrm{C}$. Dissolution was carried out using Phosphate buffer $\mathrm{pH} 7.4$ as dissolution medium. $5 \mathrm{~mL}$ samples were withdrawn at every $5 \mathrm{~min}$ and analyzed using UV spectrophotometer (UV 1800, Shimadzu, Japan) 274nm. Dissolution study was carried out in triplicate and average was considered.

\section{Effect on blood glucose level}

The animal study was approved by Institutional Animal Ethical Committee (CIP/IAEC/2015-16/070). Wistar albino rats (150-250g) were used for this study. Diabetes was induced in rats by a single intra peritoneal injection of streptozotocin at $60 \mathrm{mg} / \mathrm{kg}$ body weight in freshly prepared citrate buffer $\mathrm{pH} 4.5$. The animals were divided into four groups $(n=6)$. Group I was treated as normal group, normally fed, neither diabetes induced nor treated. Group II, Diabetic control group treated only with vehicle. Group III, Treated with $5 \mathrm{mg} / \mathrm{kg}$ Glipizide administered orally and Group IV, Treated with formulation F4 containing $3 \mathrm{mg} / \mathrm{kg}$ equivalent of glipizide

\section{Statistical analysis}

Data were statically evaluated by using one way ANOVA. Wherever the ANOVA values were found to be significant Duncan's new multiple range test (DMRT) was applied (SPSS statistics software). The values were considered significant when $\mathrm{P}<0.05$

\section{RESULT AND DISCUSSION}

Diabetes has taken a shape of endemic. World Health Organization in its global report in Diabetes reports that 1.5 millions deaths were caused by diabetes alone in 2014. The number of diabetics has increased to 422 million in 2014 from 108 million in 1980 (Media Centre , 2016). There are number of literatures which reveal the antidiabetic activity of HR leaves. The aim of this research work is to formulate and evaluate glipizide tablets containing HRM as binder. Glipizide tablet was formulated by wet variation method. Amount of HRM was varied in formulations. The prepared tablets were subjected various evaluation parameters.

Average thickness of tablets varies from $3.36 \pm 0.03$ to $3.45 \pm 0.02 \mathrm{~mm}$. Deviation in weight variation test and friability is well within the permission limit of tablets as per USP. Average hardness of the tablet was found to be $5.0 \pm 0.14$ to $5.8 \pm 0.24 \mathrm{~kg} / \mathrm{cm}^{2}$. Disintegration time was found to be from $4.24 \pm 0.12$ to $5.76 \pm 0.22 \mathrm{~min}$. Results of various parameters (Table II).

Drug polymer compatibility was determined by comparing FTIR spectrum of pure glipizide and formulations. 


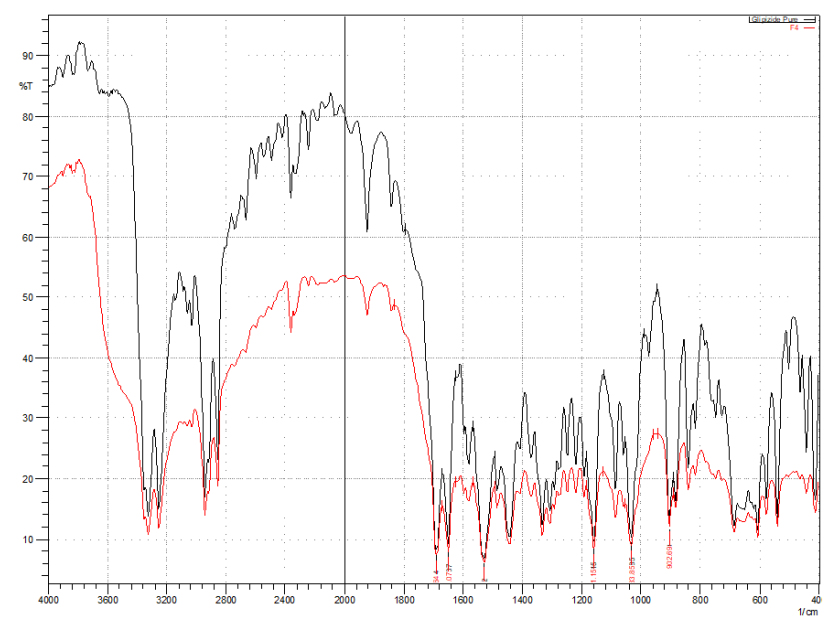

Figure 1: Comparison of FTIR spectrum of pure glipizide \& formulation F4

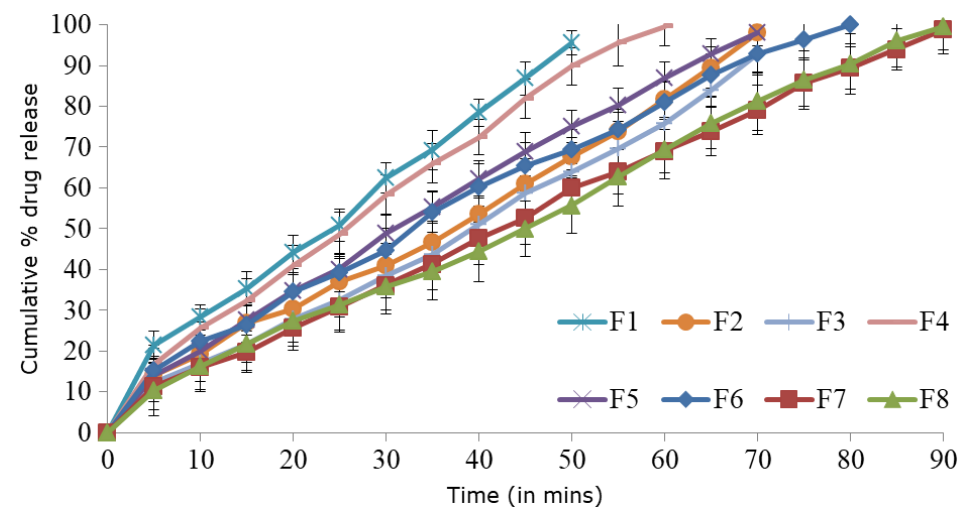

Figure 2: In vitro release profile of formulations (F1 - F8)

The characteristic peaks of glipizide 1528, representing $\mathrm{C}-\mathrm{H}$ stretching (aromatic), 1690, representing $\mathrm{C}=\mathrm{O}$ amide, 1650, representing $\mathrm{C}=\mathrm{O}$ urea, $1159,1032,900 \mathrm{~cm}^{-1}$, representing $\mathrm{O}=\mathrm{S}=\mathrm{O}$ (Moffat, et al., 2011) were observed both in pure glipizide sample and the formulations (Figure 1). This indicates that no chemical incompatibility between glipizide and the excipients used exists.

In vitro drug release study was done using phosphate buffer $\mathrm{pH}$ 7.4. During this study, it was decided to check whether the formulation could sustain the release of drug. However, it was observed that the formulation could not sustain the release the drug. Then the samples were withdrawn in $5 \mathrm{~min}$ interval for $90 \mathrm{~min}$ and fresh phosphate buffer $\mathrm{pH} 7.4$ was added to maintain the sink condition. The withdrawn sample was analyzed using UV spectro- photometer at $274 \mathrm{~nm}$. The result of dissolution study (Figure 2). As the concentration of HRM was increased in the formulation, the release of glipizide from the formulation was reduced. F7 \& F8 containing higher amount of HRM, sustains the release of glipizide till $90 \mathrm{~min}$. However, based on results of all the physicochemical and in vitro release, F4 was selected for conducting antidiabetic study.

Diabetes was induced by single intra peritoneal injection of streptozotocin at $60 \mathrm{mg} / \mathrm{kg}$. Blood glucose level (Table III) of Group I was normal $(83.20 \pm 2.24)$ on the day of commencement and remained normal throughout the completion of experiment. Group II was treated as diabetic control and didn't receive any treatment. It exhibited hyperglycemia on the first day and continued to be hyperglycaemic throughout the study. 
Table III. Effect on blood glucose level of the experimental groups

\begin{tabular}{lccccc}
\hline \multirow{2}{*}{ Treatment } & \multicolumn{5}{c}{ Blood glucose profile post treatment (mg/d) (day) } \\
\cline { 2 - 6 } & $\mathbf{0}$ & $\mathbf{7}$ & $\mathbf{1 4}$ & $\mathbf{2 1}$ & $\mathbf{2 8}$ \\
\hline Group I & $83.20 \pm 2.24$ & $84.43 \pm 2.56$ & $82.28 \pm 3.48$ & $83.44 \pm 2.04$ & $84.38 \pm 2.47$ \\
Group II & $361.20 \pm 2.95$ & $431.25 \pm 3.31$ & $417.32 \pm 4.14$ & $434.76 \pm 3.22$ & $446.76 \pm 2.19$ \\
Group III & $309.54 \pm 5.44$ & $231.11 \pm 1.84$ & $202.58 \pm 2.79$ & $168.37 \pm 2.26$ & $114.58 \pm 3.48$ \\
Group IV & $332.00 \pm 1.33$ & $253.65 \pm 3.63$ & $188.32 \pm 1.22$ & $112.58 \pm 3.82$ & $82.58 \pm 2.19$ \\
\hline
\end{tabular}

Values are mean \pm S.E. from 6 rats of each group; All values are significant at $\mathrm{P}<0.05$ compared with Group II (Diabetic control)

Group III rats were administered with glipizide and blood glucose level was hyperglycaemic (309.54 \pm 5.44$)$ on day one. However, it was reduced to non - diabetic levels on completion of experiment. Hyperglycemic status of Group IV rats was reduced to normal on completion of experiment. It was observed that the formulation, F4, was exhibiting promising result and could reduce elevated glucose level to lower levels than in Group III. Group IV animals were treated with lesser amount of glipizide than group III animals. However, group IV animal shows better glucose lowering activity compared to glipizide alone. This may be due to the fact that HR has antidiabetic activity as reported in many literatures and the mucilage extracted from HR may have acquired the antidiabetic property. This could have potentiated the activity of glipizide and thereby showing better results than the groups treated with glipizide alone.

\section{CONCLUSION}

It has been demonstrated in this study that HRM can be used as binder for formulation of glipizide tablets. The antidiabetic effect of formulation F4 reveals that the formulation exhibits better hypoglycaemic effect than the pure glipizide. This can be due to the fact that Hibiscus rosasinensis also possess antidiabetic activity. The mucilage may have some acquired hypoglycaemic activity that potentiated the activity. This calls for recognizing the dual role of mucilage, excipients \& potentiating of antidiabetic activity. However, it is suggested that human studies with the mucilage and combinations with glipizide must be studied further. This may lead to development of useful formulation with lesser amount of oral hypoglycaemic agents and thereby better therapeutic applications and lesser side effects.

\section{ACKNOWLEDGMENT}

We would like to acknowledge Dishman Pharmaceuticals \& Chemicals Ltd., India for providing gift samples \& Columbia Institute of Pharmacy for providing all the facilities and resources to complete the research work.

\section{REFERENCES}

American Diabetes Association, 2014. Diagnosis and classification of Diabetes mellitus. Diabetes Care 37 (1): 581-590

Bahadur S., Roy A., Chanda R., Choudhury A., Das S., Saha S., Chandrakar S., Prasad P., 2014. Natural excipient develeopment: need and future. Asian J. Pharm. Res. 4 (1): 12 - 15

Kambham V., Shanthi A., 2012. Formulation and evaluation of sustained release glipizide matrix. IOSRJPBS 2 (5): 17 - 23

Media Centre. World Health Organization, 2016. (http://www.who.int/mediacentre/facts heets/fs312/en/, accessed 10 April 2016.

Moffat AC., Osselton MD., Widdop B., Watts J. (Eds.). Clarke's Analysis of Drugs \& Poisons. 4. ed. London: Pharmaceutical Press, 2, 2011.

Moqbel FS., Naik PR., Habeeb NM., Selvaraj S., 2011. Antidiabetic properties of Hibiscus rosa sinensis L. leaf extract fractions on non obese diabetic (NOD) mouse. Indian J. Exp. Biol. 49: 24 $-29$ 
Razavi M., Nyamathulla S., Karimian H., Moghadamtousi, SZ., Noordin MI., 2014. Hydrogel polysaccharides of tamarind and xanthan to formulate hydrodynamically balanced matrix tablets of famotidine. Molecules 19: 13909 13931
Sankaran M., Vadivel A., 2011. Antioxidant and antidiabetic effect of Hibiscus rosasinensis flower extract on streptozotocin induced experime ntal rats-a dose response study. Not. Sci. Biol. 3 (4): $13-21$ 